\title{
Doença Cria Giz Ascosphaera apis (Maassen ex Claussen) Olive \& Spiltoir em abelhas Apis mellifera L. na Depressão Central do Rio Grande do Sul
}

\author{
Chalk brood disease Ascosphaera apis (Maassen ex Claussen) Olive \& Spiltoir in the honey bee \\ Apis mellifera L. in Central Depression of Rio Grande do Sul
}

\author{
Guido Laércio Bragança Castagnino ${ }^{1}$ Silvia Regina da Cunha Funari ${ }^{2}$ Elena Blume $^{3}$ \\ Miguelangelo Ziegler Arboitte ${ }^{4}$ Maria Nevis Weber $^{3}$
}

\begin{abstract}
A ocorrência da doença apícola “cria giz”, em colonias de abelhas Apis mellifera no apiário do Departamento de Zootecnia da Universidade Federal de Santa Maria (UFSM), RS, Brasil, foi constatada em 2004. Foram coletadas amostras de crias de abelhas duras e mumificadas em favos falhados nas colônias com pequena população. Essas amostras foram analisadas no Laboratório de Fitopatologia do Departamento de Defesa Fitossanitária da UFSM, onde se observou a presença de estruturas fúngicas com formação típica do fungo Ascosphaera apis, conhecido como causador da doença "cria giz”. Até então não existiam notificações da presença dessa doença na região central do Estado do Rio Grande do Sul, o que pode caracterizar um avanço dessa enfermidade para o interior, a partir de regióes próximas à fronteira com o Uruguai e a Argentina.
\end{abstract}

Palavras-chave: patologia apícola, fungo, mumificação.

\section{ABSTRACT}

The occurrence of chalk brood disease in colonies of the honey bee Apis mellifera located at the apiary of the Department of Zootecnia of the Federal University of Santa Maria (UFSM), Brazil, was evidenced in 2004. Hard and mummified honey bee larvae were collected from failed combs found in poorly populated colonies. These samples were analyzed in the Laboratory of Phytopathology, at the Plant Protection Department (UFSM), where the presence of fungal structures typical of Ascosphaera apis were observed. This fungus is known to cause chalk-brood disease. This is the first record of the presence of this disease in the central region of the State of
Rio Grande do Sul, Brazil, characterizing the dissemination of the disease coming from the border with Uruguay and Argentina.

Key words: honey bees pathology, fungus, mummified.

Originalmente conhecido como Pericystis apis e posteriormente reclassificado como Ascosphaera apis (SPILTOIR, 1955; SPILTOIR \& OLIVE, 1955), esse fungo caracteriza-se por causar mortalidade nas crias de abelha da espécie Apis mellifera. As larvas infectadas geralmente morrem nos dois primeiros dias, após serem operculadas nas suas células, na fase de pupa (BAILEY \& BALL, 1991). Essas crias inicialmente apresentam coloração branca e, em fase mais adiantada da doença, algumas continuam brancas, mas outras tornam-se cinza-escuras ou quase pretas. O fungo Ascosphaera apis apresenta duas fases distintas de vida: uma vegetativa ou micelial e outra reprodutiva, na qual são formados os ascósporos, que são os propágulos responsáveis pela disseminação da doença (BAILEY \& BALL, 1991). Essas larvas contaminam-se após ingerirem alimento com os esporos de Ascosphaera apis, que germinam no lúmen do intestino das larvas (HEATH \& GAZE, 1987) com crescimento e desenvolvimento do micélio, particularmente na parte

\footnotetext{
'Programa de Pós-graduação em Zootecnia, Universidade Estadual Paulista (UNESP). Rua José Vadilletti, 22, Parque Residencial Primavera, 18600-300, Botucatu, SP, Brasil. E-mail: gcastagnino@bol.com.br. Autor para correspondência.

${ }^{2}$ Departamento de Produção Animal, Faculdade de Medicina Veterinária e Zootecnia (FMVZ), UNESP, Botucatu, SP, Brasil.

${ }^{3}$ Departamento de Defesa Fitossanitária, Universidade Federal de Santa Maria (UFSM), Santa Maria, RS, Brasil.

${ }^{4}$ Departamento de Zootecnia, UFSM, Santa Maria, RS, Brasil.
} 
posterior do intestino da cria. Quando ocupam todo o corpo das larvas, estas ficam ressecadas, mumificadas e duras, semelhantes a um diminuto bastão de giz, o que motivou a proposição do nome da doença (BAILEY \& BALL, 1991).

A "cria giz" ocorre amplamente em regiões temperadas do Hemisfério Norte, mas tem se disseminado para outros países (BAILEY \& BALL, 1991). Segundo HEATH (1985), a partir da década de 70, ela foi detectada no Japão, nas Filipinas, na América Central, na Argentina e no México, onde foi considerada a doença infecciosa mais difundida entre as abelhas Apis mellifera (WILSON et al., 1984).

No Brasil, a "cria giz" foi recentemente relatada em três casos isolados: em Minas Gerais (CASTAGNINO et al., 2004), em São Paulo (ROCHA et al., 1998) e no Rio Grande do Sul (SATTLER et al., 1998). Neste último, a doença foi diagnosticada em apiários localizados no município de São Gabriel, cujos apicultores faziam migração para regiões perto da fronteira com o Uruguai e a Argentina.

Durante os manejos nas colônias de Apis mellifera africanizadas no Laboratório de Apicultura do Departamento de Zootecnia da Universidade Federal de Santa Maria (UFSM), foi constatada, em duas colônias com população fraca, a presença de favos falhados com grande quantidade de larvas e pupas mortas. As pupas apresentavam-se com a coloração branca-opaca, endurecidas e mumificadas dentro dos opérculos, com sintomas típicos da doença "cria giz", sendo que algumas eram removidas até o alvado pelas abelhas operárias. Algumas amostras de crias mumificadas de coloração branca e escura (Figura 1) foram coletadas e analisadas no Laboratório da Fitopatologia do Departamento de Agronomia da Universidade Federal de Santa Maria. Após exame sob microscópio ótico, constatou-se que elas se apresentavam infectadas com fungo no estádio vegetativo. Algumas pupas mumificadas foram então depositadas no interior de placas de Petri contendo ágar-água como meio de cultura, depois foram seladas com filme de PVCe incubadas a $25^{\circ} \mathrm{C}$ por três dias para estimular a produção de esporos do fungo. Dois dias após, observou-se o surgimento de pontos escuros no meio de ágar-água. Essas estruturas eram os ascomas marrons semelhantes a cistos, típicos de Ascosphaera apis. Dentro destes, havia ascos e ascósporos hialinos, que posteriormente foram

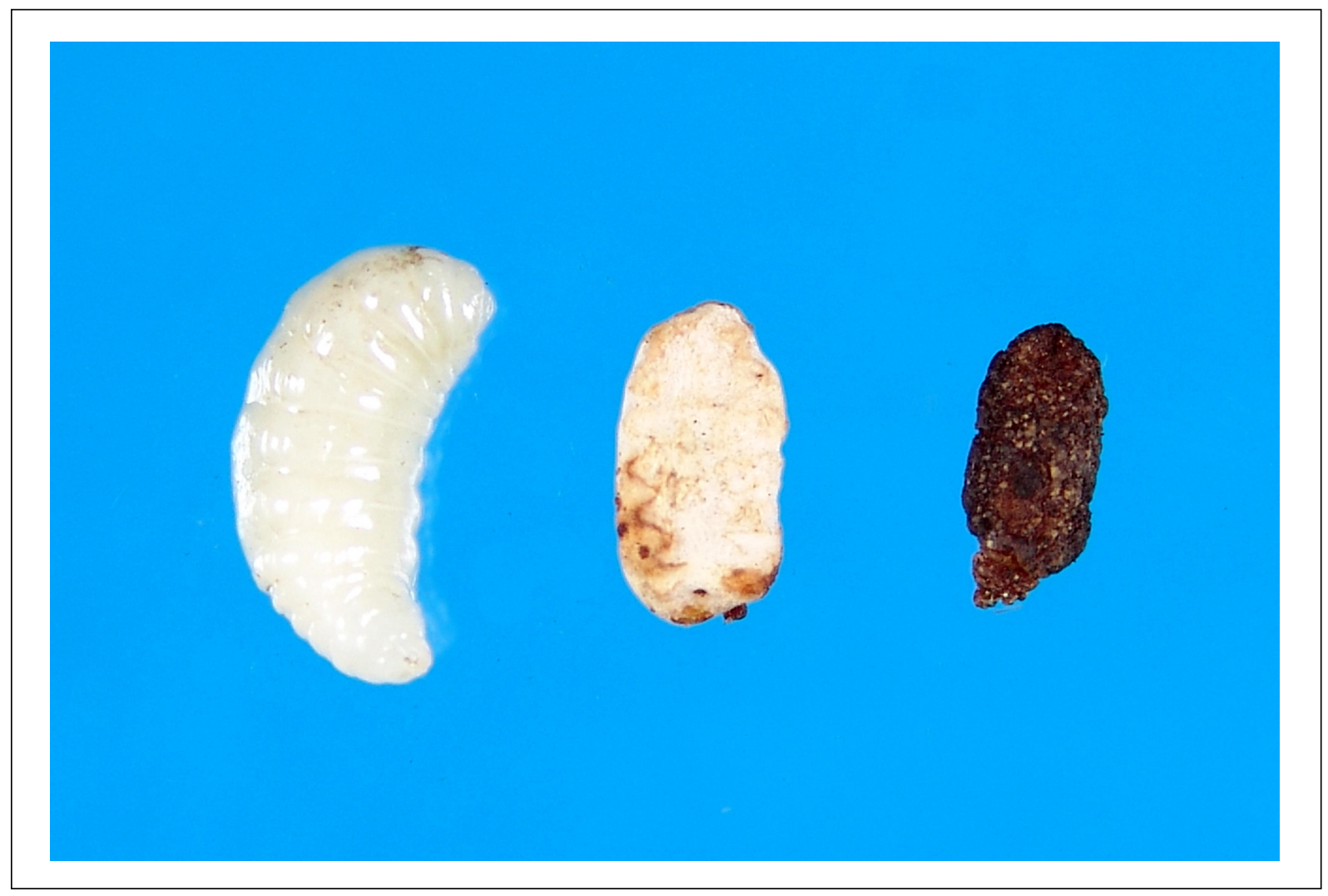

Figura 1 - Crias de abelhas Apis mellifera apresentando três situações: à esquerda, uma cria sadia na fase de pupa; ao centro, uma cria morta e mumificada pelo fungo e, à direita, uma cria de coloração escura já com formação de esporos do fungo Ascosphaera apis.

Ciência Rural, v.36, n.6, nov-dez, 2006. 
fotografados e analisados, confirmando assim a presença do agente etiológico da "cria giz", Ascosphaera apis, nas amostras. Quando na sua forma vegetativa, o fungo Ascosphaera apis não é infectivo tanto para as crias como para as abelhas adultas. No entanto, se estiver na fase de esporo, é facilmente transmitido para as crias, quando estas são alimentadas pelas operárias, ou se o apicultor utilizar pólen contaminado com os esporos para alimentar as colônias.

Possivelmente, o que pode explicar a dispersão do fungo Ascosphaera apis é a migração de colônias entre a região central do Rio Grande do Sul e áreas próximas à fronteira com o Uruguai e a Argentina. Segundo Castagnino (2004 - Informe verbal), essa praga já pode ser encontrada em alguns apiários nos municípios de Cacequi e Santiago, ambos no Estado do Rio Grande do Sul.

Em muitos casos, os apicultores desconhecem e não sabem diagnosticar os sintomas dessa doença, atribuindo a mortalidade das crias às baixas temperaturas, não tomando as medidas necessárias para evitar novas contaminações ao manejar as colméias não-infectadas. Cuidados no manejo das colméias, como não as alimentar com pólen e evitar colocá-las diretamente no chão, são importantes na prevenção de enfermidades, principalmente as provenientes de estresse, como a "cria pútrida européia", a nosemose e a "cria giz" (DE JONG, 1976; DE JONG \& MORSE, 1976).Como forma de atenuar a dispersão da praga para o interior do Estado, indica-se que os apicultores façam revisões periódicas nas áreas de cria, aprendam a reconhecer os sintomas da doença "cria giz", fiquem atentos ao fazer apicultura migratória para as regiões onde a praga já foi constatada e busquem fazer seleção genética de colméias mais resistentes às doenças.

\section{INFORMEVERBAL}

Rua José Vadilletti, 22, Parque Residencial Primavera, 18600300, Botucatu - SP. E-mail: gcastagnino@bol.com.br. Palestra sobre "Doenças de cria, pragas e predadores de abelhas", no II Encontro Regional de Apicultores em Ijuí, RS, realizado em 14 de maio de 2004.

\section{REFERÊNCIAS}

BAILEY, L.; BALL, B.V. Honey bee pathology. London: Academic, 1991. 193p.

CASTAGNINO, G.L.B. et al. Primeiro relato da doença "cria giz" em abelhas Apis mellifera no estado de Minas Gerais. Revista Ceres, Viçosa, 2004. (Artigo aceito para publicação em 27.02.2004. No prelo).

DE JONG, D. Experimental enhancement of chalk brood infections. Bee World, v.57, p.114-115, 1976.

DE JONG, D.; MORSE, R.A. Chalk brood: a new disease of honey bees in the U.S. New Yorks Food and Life Sciences Quartely, v.9, n.2. p.12-14, 1976

HEATH, L.A.F. Occurrence and distribution of chalk brood disease of honeybees. Bee World, n.66, p.9-15, 1985.

HEATH, L.A.F.; GAZE, B.M. Carbon dioxide activation of spores of the chalkbrood fungus Ascosphaera apis. Journal of Apicultural Research, n.26, p.243-246, 1987.

ROCHA, H.C. et al. Identificação do fungo Ascosphaera apis em colméias de abelhas Apis mellifera L. no Estado de São Paulo. In: CONGRESSO BRASILEIRO DE APICULTURA, 12., 1998, Salvador, BA. Anais... Salvador: CBA, 1998. p.247.

SATTLER, A. et al. Ocorrência de cria giz (Ascosphaera apis) em apiários no Rio Grande do Sul. In: CONGRESSO BRASILEIRO DE APICULTURA, 12., 1998, Salvador, BA. Anais... Salvador: CBA, 1998. p.257.

SPILTOIR, C.F. Life cycle of Ascosphaera apis (Pericystis apis). American Journal of Botany, n.42, p.501-508, 1955.

SPILTOIR, C.F.; OLIVE. L.S. A reclassification of the genus Pericystis Betts. Mycologia, n. 47, p.238-244, 1955.

WILSON, W.T. et al. The occurrence of brood diseases and the absence of the Varroa mite in honeybees from Mexico. American Bee Journal, n.124, p.51-53, 1984. 